\title{
ESTIMASI PARAMETER PADA SISTEM MODEL PERSAMAAN SIMULTAN DATA PANEL DINAMIS DENGAN METODE 2 SLS GMM-AB
}

\author{
Arya Fendha Ibnu Shina \\ Institut Agama Islam Negeri (IAIN) Salatiga \\ e-mail: aryafendha@gmail.com
}

DOI: 10.14710/medstat.11.2.79-91

\section{Article Info:}

Received: 27 January 2018

Accepted: 10 September 2018

Available Online: 4 March 2019

Keywords: 2 SLS GMM-AB, Arellano and Bond estimator, Dynamic Panel Data, Simultaneous Equations

\begin{abstract}
Single equation models ignore interdependencies or two-way relationships between response variables. The simultaneous equation model accommodates this two-way relationship form. Two Stage Least Square Generalized Methods of Moment Arellano and Bond (2 SLS GMM-AB) is used to estimate the parameters in the simultaneous system model of dynamic panel data if each structural equation is exactly identified or over identified. In the simultaneous equation system model with dynamic panel data, each structural equation and reduced form is a dynamic panel data regression equation. Estimation of structural equations and reduced form using Ordinary Least Square (OLS) resulted biased and inconsistent estimators. Arellano and Bond GMM method (GMM AB) estimator produces unbiased, consistent, and efficient estimators.The purpose of this paper is to explain the steps of 2 SLS GMM-AB method to estimate parameter in simultaneous equation model with dynamic panel data.
\end{abstract}

\section{PENDAHULUAN}

Model persamaan tunggal yang sering digunakan mengabaikan interdependensi antara variabel. Dalam kasus ekonomi misalnya, sering ditemui variabel yang memiliki hubungan dua arah atau saling mempengaruhi. Hubungan ini dapat terangkum di dalam satu sistem persamaan simultan. Dalam persamaan simultan terdapat beberapa persamaan, dimana jumlah persamaan sama dengan jumlah variable endogen. Variabel lainnya adalah variabel yang berkontribusi menjelaskan model yaitu variabel predetermined (ditetapkan mula-mula). Variabel predetermined terdiri dari dua variabel, yaitu variabel eksogen dan variabel endogenous lagged (endogen lembam). Variabel endogenous lagged ini berkorelasi dengan error. Dengan demikian estimasi menggunakan OLS akan menghasilkan estimator yang bias dan tidak konsisten. Untuk mengatasi hal tersebut Anderson dan Hsiao (1982) menyarankan untuk menggunakan metode estimasi variabel instrumen, yakni dengan menginstrumenkan variabel yang berkorelasi dengan error. Kelemahan dari metode ini adalah menghasilkan estimator yang tidak efisien walaupun tetap tak bias dan konsisten. Metode variabel instrumen Anderson dan Hsiao ini selanjutnya dikembangkan oleh Arellano dan Bond (1991) yang menggunakan prinsip 
GMM untuk mengestimasi parameter pada model data panel dinamis. Metode estimasi ini selanjutnya disebut sebagai GMM Arellano-Bond.

Model panel dinamis sering digunakan dalam penelitian di bidang ekonomi. Dalam melakukan penelitian yang melibatkan variabel ekonomi, tidak cukup hanya dengan menggunakan data cross section karena perlu dilakukan observasi perilaku unit penelitian pada berbagai periode waktu. Data yang merupakan gabungan antara data cross section dan data time series disebut data panel. Baltagi (2005) menyatakan bahwa ada beberapa keuntungan menggunakan data panel, yaitu data bersifat heterogen, lebih informatif, bervariasi, derajat bebas lebih besar, lebih efisien, lebih unggul dalam mempelajari perubahan dinamis, lebih dapat mendeteksi dan mengukur pengaruh-pengaruh yang tidak terobservasi pada data cross section murni dan time series murni, dan meminimalisasi bias. Di samping itu, hubungan variabel-variabel ekonomi pada dasarnya bersifat dinamis yaitu variabel tidak hanya dipengaruhi oleh variabel itu sendiri pada waktu yang sama tetapi juga pada waktu sebelumnya. Untuk mengestimasi parameter pada persamaan regresi data panel dinamis dapat menggunakan GMM (Generalized Method of Moment) ArellanoBondyang menghasilkan penduga tidak bias, konsisten, dan efisien.Estimasi parameter pada persamaan simultan data panel dinamis dapat menggunakan kombinasi metode GMM Arellano-Bond dan Two Stage Least Square (2 SLS) apabila setiap persamaan strukturalnya teridentifikasi secara tepat atau berlebihan.Tujuan tulisan ini adalah kajian teoritis untuk menjabarkan langkah-langkah estimasi parameter pada model persamaan simultan data panel dinamis dengan 2 SLS GMM-AB.

\section{TINJAUAN PUSTAKA}

\subsection{Regresi Data Panel}

Salah satu struktur data yang sering digunakan dalam studi ekonomi adalah data panel. Data panel merupakan data dari beberapa individu atau objek yang diamati dalam suatu periode waktu. Jika dimiliki sebanyak $N$ individu dimana $i=1,2,3, \ldots, N$ dalam $T$ waktu dimana $t=1,2,3, \ldots, T$ maka observsi total yang dimiliki adalah sebanyak $N \times T$.

Model regresi linier data panel pada pengamatan ke- $i$ dan waktu ke- $t$ dengan $K$ buah variabel prediktor, direpresentasikan sebagai berikut:

dengan:

$$
y_{i, t}=\alpha+\boldsymbol{x}_{i, t}^{\prime} \boldsymbol{\beta}+u_{i, t} ; \quad i=1,2, \ldots, N ; \quad t=1,2, \ldots T
$$

$y_{i, t}=$ variabel dependen, yang merupakan unit cross section ke- $i$ untuk periode ke- $t$

$\alpha=$ skalar

$\boldsymbol{x}_{i, t}^{\prime}=$ vektor dari variabel independen berukuran $1 \times K$

$\boldsymbol{\beta}=$ vektor konstanta yang berukuran $K \times 1$

$u_{i, t}=$ error

Secara umum model regresi linier data panel yang sering digunakan adalah model regresi data panel komponen error satu arah (one-way error component regression model), dimana error terdiri dari:

$$
u_{i, t}=e_{i}+v_{i, t}
$$

$e_{i}$ adalah komponen error spesifik individu dan $v_{i, t}$ merupakan komponen error yang bersifat umum (Baltagi, 2005).

\subsection{Regresi Data Panel Dinamis}

Salah satu model yang sering digunakan untuk menggambarkan hubungan-hubungan antar variabel ekonomi adalah model data panel dinamis. Banyak variabel ekonomi yang 
bersifat dinamis artinya nilai suatu variabel tidak hanya dipengaruhi oleh nilai variabel lain namun juga nilai variabel yang bersangkutan di masa lalu. Model panel dinamis digambarkan dalam persamaan di bawah ini:

$$
y_{i, t}=\delta y_{i, t-1}+\boldsymbol{x}_{i, t}^{\prime} \boldsymbol{\beta}+u_{i, t} \quad i=1,2, \ldots, N ; \quad t=1,2, \ldots T
$$

dengan $\delta$ merupakan skalar, $x_{i, t}^{\prime}$ adalah vektor variabel independen berukuran $1 \times K$, dan $\beta$ adalah vektor konstanta yang berukuran $K \times 1$. Diasumsikan $u_{i t}$ merupakan komponen error satu arah seperti yang dituliskan pada persamaan (2) dan diasumsikan $e_{i} \sim \operatorname{IIDN}\left(0, \sigma_{e}^{2}\right)$ dan $v_{i, t} \sim \operatorname{IIDN}\left(0, \sigma_{v}^{2}\right)$. Lai dkk (2008) mengatakan bahwa dalam model regresi panel dinamis koefisian $\beta$ juga merupakan efek jangka pendek dari perubahan $x_{i, t}$ sedangkan $\left(\frac{\beta}{(1-\delta)}\right)$ merupakan efek jangka panjang dari perubahan $x_{i, t}$.

Apabila $y_{i, t}$ adalah fungsi dari $u_{i, t}$ maka sebagai akibatnya $y_{i, t-1}$ juga merupakan fungsi dari $u_{i, t}$. Dengan kata lain, regressor pada sisi kanan (endogen eksplanatori) $y_{i, t-1}$ berkorelasi dengan $u_{i, t}$. Penggunakan metode estimasi panel statis seperti OLS pada model persamaan panel dinamis akan bias dan tidak konsisten (Baltagi, 2005).

\subsection{Generalized Methode of Moment Arellano-Bond}

Pada penelitian Arellano dan Bond (1991) dilakukan perbandingan antara metode instrumen variabel Anderson-Hsiao dan GMM Arellano-Bond. Perbandingan tersebut dilakukan dengan cara melakukan simulasi Monte Carlo dan mengaplikasikan kedua metode tersebut untuk mengestimasi model ketenagakerjaan di Inggris. Simulasi Monte Carlo dilakukan sebanyak 100 ulangan, 7 periode waktu, dan 2 parameter, sedangkan untuk memodelkan ketenagakerjaan di Inggris, Arellano dan Bond (1991) menggunakan data panel tidak seimbang (unbalanced panel) dari 140 perusahaan pada periode 19791984. Hasil simulasi dan estimasi pada model ketenagakerjaan menghasilkan varian estimator GMM Arellano-Bond yang lebih kecil daripada varian estimator instrumen variabel Anderson dan Hsiao. Berdasarkan penelitian ini, dapat disimpulkan bahwa estimator GMM Arellano-Bond lebih efisien dibandingkan estimator instrumen variabel Anderson dan Hsiao.

Untuk menggambarkan langkah-langkah metode estimasi GMM Arellano-Bond, berikut dituliskan persamaan first difference.

$$
\left(y_{i, t}-y_{i, t-1}\right)=\delta\left(y_{i, t-1}-y_{i, t-2}\right)+\left(v_{i, t}-v_{i, t-1}\right) \quad ; i=1,2, \ldots, N ; t=1,2, \ldots T
$$

- Untuk $t=3$, maka

$$
\left(y_{i, 3}-y_{i, 2}\right)=\delta\left(y_{i, 2}-y_{i, 1}\right)+\left(v_{i, 3}-v_{i, 2}\right)
$$

Pada kasus $t=3, y_{i, 1}$ merupakan variabel instrumen yang tepat, karena berkorelasi dengan $\left(y_{i, 2}-y_{i, 1}\right)$,dan tidak berkorelasi dengan $\left(v_{i, 3}-v_{i, 2}\right)$.

- Untuk $t=4$, maka

$$
\left(y_{i, 4}-y_{i, 3}\right)=\delta\left(y_{i, 3}-y_{i, 2}\right)+\left(v_{i, 4}-v_{i, 3}\right)
$$

Pada kasus $t=4, y_{i, 1}$ dan $y_{i, 2}$ merupakan variabel instrumen yang tepat, karena berkorelasi dengan $\left(y_{i, 3}-y_{i, 2}\right)$, dan tidak berkorelasi dengan $\left(v_{i, 4}-v_{i, 3}\right)$.

Berdasarkan kasus pada $t=3$ dan $t=4$ dapat disimpulkan bahwa setiap penambahan satu periode waktu, terdapat penambahan satu variabel instrumen. Dengan 
demikian, sampai pada periode $k e-T$ terdapat $\left(y_{i, 1}, y_{i, 2}, \ldots, y_{i, T-2}\right)$ himpunan variabel instrumen yang tepat. Pada metode GMM Arellano-Bond, matriks instrumen $\boldsymbol{Z}_{i}$ yang digunakan adalah

$$
\boldsymbol{Z}_{i}=\left[\begin{array}{ccll}
{\left[y_{i, 1}\right]} & 0 & \ldots & 0 \\
0 & {\left[y_{i, 1}, y_{i, 2}\right]} & \ldots & 0 \\
\vdots & \vdots & \ddots & 0 \\
0 & 0 & 0 & \left.0 y_{i, 1}, \ldots, y_{i, T-2}\right]
\end{array}\right]
$$

Estimasi parameter Arellano-Bond menggunakan prinsip GMM untuk mendapatkan taksiran yang konsisten. Dengan $\boldsymbol{E}\left(\boldsymbol{Z}_{i}^{\prime} \boldsymbol{\Delta} \boldsymbol{v}_{i}\right)=\mathbf{0}$ (syarat $\boldsymbol{Z}_{i}$ sebagai matriks instrumen) maka momen kondisi dari populasi adalah:

$$
E\left(g_{i}(\delta)\right)=E\left(\boldsymbol{Z}_{i}^{\prime} \boldsymbol{\Delta} \boldsymbol{v}_{\boldsymbol{i}}\right)=E\left(\boldsymbol{Z}_{i}^{\prime}\left(\Delta \boldsymbol{y}_{i}-\delta \boldsymbol{\Delta} \boldsymbol{y}_{i, t-1}\right)\right)=0
$$

Momen kondisi dari sampel

$$
\bar{g}(\delta)=N^{-1} \sum_{i=1}^{N} \boldsymbol{Z}_{i}^{\prime}\left(\Delta \boldsymbol{y}_{i}-\delta \boldsymbol{\Delta} \boldsymbol{y}_{i, t-1}\right)
$$

Didefinisikan matriks $\widehat{\boldsymbol{W}}$ yaitu taksiran tak bias dan konsisten untuk matriks bobot $\boldsymbol{W}_{(L \times L)}$ dimana $L$ adalah jumlah variabel instrumen. Kemudian dibangun suatu fungsi GMM yang merupakan fungsi kuadratik dari momen sampel. Fungsi tersebut adalah sebagai berikut:

$$
J(\delta)=\bar{g}(\delta)^{\prime} \widehat{\boldsymbol{W}} \bar{g}(\delta)
$$

Maka,

$$
\begin{aligned}
J(\delta)= & {\left[N^{-1} \sum_{i=1}^{N} \boldsymbol{Z}_{i}^{\prime}\left(\Delta \boldsymbol{y}_{i}-\delta \boldsymbol{\Delta} \boldsymbol{y}_{i, t-1}\right)\right]^{\prime} \widehat{\boldsymbol{W}}\left[N^{-1} \sum_{i=1}^{N} \boldsymbol{Z}_{i}^{\prime}\left(\Delta \boldsymbol{y}_{i}-\delta \Delta \boldsymbol{y}_{i, t-1}\right)\right] } \\
= & {\left[N^{-1}\left(\sum_{i=1}^{N} \boldsymbol{Z}_{i}^{\prime} \Delta \boldsymbol{y}_{i}\right)-N^{-1}\left(\sum_{i=1}^{N} \boldsymbol{Z}_{i}^{\prime} \delta \Delta \boldsymbol{y}_{i, t-1}\right)\right]^{\prime} } \\
& \widehat{\boldsymbol{W}}\left[N^{-1}\left(\sum_{i=1}^{N} \boldsymbol{Z}_{i}^{\prime} \Delta \boldsymbol{y}_{i}\right)-N^{-1}\left(\sum_{i=1}^{N} \boldsymbol{Z}_{i}^{\prime} \delta \Delta \boldsymbol{y}_{i, t-1}\right)\right] \\
= & \left(N^{-1} \sum_{i=1}^{N} \Delta \boldsymbol{y}_{i}^{\prime} \boldsymbol{Z}_{i}\right) \widehat{\boldsymbol{W}}\left(N^{-1} \sum_{i=1}^{N} \boldsymbol{Z}_{i}^{\prime} \Delta \boldsymbol{y}_{i}\right) \\
& -2\left(N^{-1} \sum_{i=1}^{N} \boldsymbol{\Delta y}_{i, t-1}{ }^{\prime} \delta^{\prime} \boldsymbol{Z}_{i}\right) \widehat{\boldsymbol{W}}\left(N^{-1} \sum_{i=1}^{N} \boldsymbol{Z}_{i}^{\prime} \Delta \boldsymbol{y}_{i}\right) \\
& +\left(N^{-1} \sum_{i=1}^{N} \boldsymbol{\Delta} \boldsymbol{y}_{i, t-1}{ }^{\prime} \delta^{\prime} \boldsymbol{Z}_{i}\right) \widehat{\boldsymbol{W}}\left(N^{-1} \sum_{i=1}^{N} \boldsymbol{Z}_{i}^{\prime} \delta \boldsymbol{\Delta} \boldsymbol{y}_{i, t-1}\right)
\end{aligned}
$$

Estimator GMM untuk $\delta$ didapatkan dengan cara meminimumkan fungsi kuadrat terboboti $J(\delta)$. 


$$
\begin{aligned}
& \frac{\partial J(\delta)}{\partial \hat{\delta}}=0 . \\
& \frac{\partial J(\delta)}{\partial \hat{\delta}}=-2\left(N^{-1} \sum_{i=1}^{N} \boldsymbol{\Delta y}_{i, t-1}{ }^{\prime} \boldsymbol{Z}_{i}\right) \widehat{\boldsymbol{W}}\left(N^{-1} \sum_{i=1}^{N} \boldsymbol{Z}_{i}^{\prime} \Delta \boldsymbol{y}_{i}\right) \\
& +2\left(N^{-1} \sum_{i=1}^{N} \boldsymbol{\Delta y}_{i, t-1}{ }^{\prime} \boldsymbol{Z}_{i}\right) \widehat{\boldsymbol{W}}\left(N^{-1} \sum_{i=1}^{N} \boldsymbol{Z}_{i}^{\prime} \hat{\delta} \boldsymbol{\Delta} \boldsymbol{y}_{i, t-1}\right)=0 \\
& \hat{\delta}=\left[\left(N^{-1} \sum_{i=1}^{N} \Delta \boldsymbol{y}_{i, t-1}^{\prime} \boldsymbol{Z}_{i}\right) \widehat{\boldsymbol{W}}\left(N^{-1} \sum_{i=1}^{N} \boldsymbol{Z}_{i}^{\prime} \boldsymbol{\Delta} \boldsymbol{y}_{i, t-1}\right)\right]^{-1} \\
& {\left[\left(N^{-1} \sum_{i=1}^{N} \boldsymbol{\Delta} \boldsymbol{y}_{i, t-1}{ }^{\prime} \boldsymbol{Z}_{i}\right) \widehat{\boldsymbol{W}}\left(N^{-1} \sum_{i=1}^{N} \boldsymbol{Z}_{i}^{\prime} \Delta \boldsymbol{y}_{i}\right)\right]}
\end{aligned}
$$

Estimator $\hat{\delta}$ merupakan estimator yang konsisten tidak tergantung bagaimana pemilihan bobot $\widehat{W}$. Estimasi parameter pada persamaan (5) disebut sebagai one step consistent estimator (Baltagi, 2005).

Pemilihan $\widehat{\boldsymbol{W}}$ tidak akan mempengaruhi kekonsistenan estimator, namun dengan memilih $\widehat{\boldsymbol{W}}$ yang optimal akan menghasilkan taksiran yang efisien. Arellano dan Bond (1991) mengusulkan bobot $\widehat{\boldsymbol{W}}$ yang optimal sebagai berikut:

$$
\widehat{W}=\widehat{\Lambda}^{-1}
$$

dengan

$$
\widehat{\Lambda}=N^{-1} \sum_{i=1}^{N} Z_{i}^{\prime} \Delta v_{i} \Delta v_{i}^{\prime} Z_{i}
$$

Sehingga dihasilkan,

$$
\begin{gathered}
\hat{\delta}=\left[\left(N^{-1} \sum_{i=1}^{N} \boldsymbol{\Delta} \boldsymbol{y}_{i, t-1}{ }^{\prime} \boldsymbol{Z}_{i}\right) \widehat{\boldsymbol{\Lambda}}^{-\mathbf{1}}\left(N^{-1} \sum_{i=1}^{N} \boldsymbol{Z}_{i}^{\prime} \boldsymbol{\Delta} \boldsymbol{y}_{i, t-1}\right)\right]^{-1} \\
{\left[( N ^ { - 1 } \sum _ { i = 1 } ^ { N } \boldsymbol { \Delta } \boldsymbol { y } _ { i , t - 1 } { } ^ { \prime } \boldsymbol { Z } _ { i } ) \widehat { \boldsymbol { \Lambda } } ^ { - \mathbf { 1 } } \left(N^{-1} \sum_{i=1}^{N} \boldsymbol{Z}_{i}^{\prime} \Delta \boldsymbol{y}_{i}\right.\right.}
\end{gathered}
$$

Estimasi parameter pada (6) disebut sebagai two step efficient GMM estimator ArellanoBond (Baltagi, 2005).

\subsection{Model Persamaan Simultan}

Model persamaan simultan memiliki lebih dari satu persamaan interdependen. Jumlah persamaan sama dengan jumlah variabel endogen. Bentuk struktural sistem persamaan simultan secara umum dengan $M$ persamaan dan $M$ variabel endogen $Y_{1}, Y_{2}, \ldots, Y_{M}$ dan sebanyak $K$ variabel eksogen $X_{1}, X_{2}, \ldots, X_{K}$ adalah sebagai berikut : 


$$
\begin{aligned}
\alpha_{11} Y_{1 i}+ & \alpha_{12} Y_{2 i}+\cdots+\alpha_{1 M} Y_{M i}+\beta_{11} X_{1 i}+\beta_{12} X_{2 i}+\cdots+\beta_{1 K} X_{K i}=u_{1 i} \\
\alpha_{21} Y_{1 i}+ & \alpha_{22} Y_{2 i}+\cdots+\alpha_{2 M} Y_{M i}+\beta_{21} X_{1 i}+\beta_{22} X_{2 i}+\cdots+\beta_{2 K} X_{K i}=u_{2 i} \\
& \cdot \\
& \cdot \\
& \cdot \\
\alpha_{M 1} Y_{1 i}+ & \alpha_{M 2} Y_{2 i}+\cdots+\alpha_{M M} Y_{M i}+\beta_{M 1} X_{M i}+\beta_{M 2} X_{M i}+\cdots+\beta_{M K} X_{K i}=u_{M i}
\end{aligned}
$$

$u_{1 i}, u_{2 i}, \ldots, u_{M i}$ merupakan variabel error dengan $i=1,2, \ldots, N$ sebagai banyaknya observasi, $\alpha_{i j}$ merupakan koefisien-koefisien dari variabel endogen dengan $m=1,2, \ldots, M$ dan $\beta_{m k}$ merupakan koefisien-koefisien variabel eksogen dengan $k=1,2, \ldots, K$.

Persamaan (7) dapat dibentuk dalam susunan matrik sebagai berikut:

$$
\left[\begin{array}{cccc}
\alpha_{11} & \alpha_{12} & \ldots & \alpha_{1 M} \\
\alpha_{21} & \alpha_{22} & \ldots & \alpha_{2 M} \\
\vdots & \vdots & \ddots & \vdots \\
\alpha_{M 1} & \alpha_{M 2} & \ldots & \alpha_{M M}
\end{array}\right]\left[\begin{array}{c}
Y_{1 i} \\
Y_{2 i} \\
\vdots \\
Y_{M i}
\end{array}\right]+\left[\begin{array}{cccc}
\beta_{11} & \beta_{12} & \ldots & \beta_{1 K} \\
\beta_{21} & \beta_{22} & \ldots & \beta_{2 K} \\
\vdots & \vdots & \ddots & \vdots \\
\beta_{M 1} & \beta_{M 2} & \ldots & \beta_{M K}
\end{array}\right]\left[\begin{array}{c}
X_{1 i} \\
X_{2 i} \\
\vdots \\
X_{K i}
\end{array}\right]=\left[\begin{array}{c}
u_{1 i} \\
u_{2 i} \\
\vdots \\
u_{M i}
\end{array}\right]
$$

selanjutnya dapat ditulis menjadi,

$$
\boldsymbol{\Gamma} \boldsymbol{Y}_{i}+\boldsymbol{B} \boldsymbol{X}_{i}=\boldsymbol{\mu}_{i}, \quad i=1,2, \ldots, N
$$

dengan $\Gamma$ adalah matrik koefisien dengan ukuran $M \times M, B$ adalah matrik koefisien dengan ukuran $M \times K, Y_{i}$ adalah vektor $M$ variabel endogen dengan ukuran $M \times 1, X_{i}$ adalah vektor $K$ variabel eksogen dengan ukuran $K \times 1, \mu_{i}$ adalah matrik structural disturbance.

Model pada persamaan (9) merupakan model lengkap yang secara umum dapat diselesaikan dengan model reduced form. Model reduced form ditulis sebagai berikut:

$$
\begin{aligned}
Y_{1 i}= & \pi_{11} X_{1 i}+\pi_{12} X_{2 i}+\cdots+\pi_{1 K} X_{K i}+v_{1 i} \\
Y_{2 i}= & \pi_{21} X_{1 i}+\pi_{22} X_{2 i}+\cdots+\pi_{2 K} X_{K i}+v_{2 i} \\
& \cdot \\
& \cdot \\
& \cdot \\
Y_{M i}= & \pi_{M 1} X_{1 i}+\pi_{M 2} X_{M i}+\cdots+\pi_{M K} X_{K i}+v_{M i}
\end{aligned}
$$

dimana $\pi$ adalah koefisien reduced form dan $v$ adalah disturbance reduced form. Persamaan (10) merupakan reduksi dari persamaan (8). Dengan mensubtitusi persamaan (8), sehingga didapatkan persamaan reduced form seperti pada persamaan (10). Persamaan (10) tersebut dapat disajikan dalam bentuk matrik, yaitu sebagai berikut:

$$
\left[\begin{array}{c}
Y_{1 i} \\
Y_{2 i} \\
\vdots \\
Y_{M i}
\end{array}\right]=\left[\begin{array}{cccc}
\pi_{11} & \pi_{12} & \ldots & \pi_{1 K} \\
\pi_{21} & \pi_{22} & \ldots & \pi_{2 K} \\
\vdots & \vdots & \ddots & \vdots \\
\pi_{M 1} & \pi_{M 2} & \ldots & \pi_{M K}
\end{array}\right]\left[\begin{array}{c}
X_{1 i} \\
X_{2 i} \\
\vdots \\
X_{K i}
\end{array}\right]+\left[\begin{array}{c}
v_{1 i} \\
v_{2 i} \\
\vdots \\
v_{M i}
\end{array}\right]
$$

dapat pula ditulis menjadi:

$$
\boldsymbol{Y}_{i}=\boldsymbol{\Pi} \boldsymbol{X}_{i}+\boldsymbol{v}_{i}, \quad i=1,2, \ldots, N
$$


dimana $\boldsymbol{\Pi}$ adalah matrik koefisien dengan ukuran $M \times K$ dan $\boldsymbol{v}_{i}$ adalah vektor disturbance dari reduced form. Dengan memperhatikan persamaan (9) maka persamaan (12) dapat ditulis menjadi

$$
\boldsymbol{Y}_{i}=-\Gamma^{-1} B X_{i}+\Gamma^{-1} \mu_{i}
$$

dengan

$$
\begin{aligned}
& \Pi=-\Gamma^{-1} B \\
& v_{i}=\Gamma^{-1} \mu_{i}
\end{aligned}
$$

Dengan asumsi bahwa $\boldsymbol{\Gamma}$ adalah matrik non-singular, maka penyelesaian variabel endogen secara eksplisit ada. Dari persamaan (13) dapat disimpulkan bahwa koefisien bentuk tereduksi merupakan fungsi dari koefisien struktural.

\subsection{Identifikasi Model Persamaan Simultan}

Identifikasi model diperlukan untuk menentukan metode estimasi yang akandigunakan. Disamping itu, dalam sistem persamaan simultan terdapat masalah yang sering dihadapi yaitu koefisien dari bentuk tereduksi (reduced form) tidak selalu dapat mengidentifikasi semua koefisien yang ada dalam persamaan struktural. Masalah ini disebut masalah identifikasi. Jika parameter dapat diestimasi dari bentuk struktural melalui bentuk tereduksi, maka dapat dikatakan bahwa persamaan tersebut teridentifikasi (identified). Jika parameter tidak dapat diestimasi dari bentuk struktural melalui bentuk tereduksi, maka dapat dikatakan bahwa persamaan tersebut tak teridentifikasi (unidentified). Persamaan yang teridentifikasi terdiri dari dua macam, yaitu teridentifikasi secara tepat (just identified/exactly identified) dan teridentifikasi secara berlebihan (overidentified).

Kaidah yang sering digunakan untuk menentukan identifikasi suatu sistem persamaan simultan adalah dengan order conditions. Untuk memahami order conditions, maka perlu dipahami beberapa notasi berikut :

1. $M$ = banyaknya variabel endogen dalam model,

2. $m=$ banyaknya variabel endogen dalam sebuah persamaan tertentu,

3. $\mathrm{K}=$ banyaknya variabel predetermined di dalam model,

4. $\mathrm{k}=$ banyaknya variabel predetermined di dalam sebuah persamaan tertentu.

Identifikasi suatu persamaan simultan dengan kaidah order conditions memberikan informasi sebuah persamaan teridentifikasi secara tepat atau teridentifikasi secara berlebihan. Jika $K-k \leq m-1$ maka dapat dikatakan bahwa persamaan itu tidak teridentifikasi, sedangkan jika $K-k=m-1$ persamaan yang teridentifikasi secara tepat, dan jika $K-k \geq m-1$ persamaan yang teridentifkasi secara berlebihan (Gujarati, 2012).

Sebagai gambaran penggunaan kaidah order conditions, maka diberikan empat contoh persamaan struktural sebagai berikut :

$$
\begin{aligned}
& Y_{1 i}-\alpha_{10}-\alpha_{12} Y_{2 i}-\alpha_{13} Y_{3 i}-\beta_{11} X_{1 i}=u_{1 i} \\
& Y_{2 i}-\alpha_{20}-\alpha_{23} Y_{3 i}-\beta_{21} X_{1 i}-\beta_{22} X_{2 i}=u_{2 i} \\
& Y_{3 i}-\alpha_{30}-\alpha_{31} Y_{1 i}-\beta_{31} X_{1 i}-\beta_{32} X_{2 i}=u_{3 i} \\
& Y_{4 i}-\alpha_{40}-\alpha_{41} Y_{1 i}-\beta_{42} X_{2 i}-\beta_{43} X_{3 i}=u_{4 i}
\end{aligned}
$$


Aturan pemeriksaan kaidah order conditions, terdapat pada Tabel 1.

Tabel 1 Kaidah Order Conditions

\begin{tabular}{cccc}
\hline Persamaan & $K-k$ & $m-1$ & Identified? \\
\hline$(16)$ & $3-1=2$ & $3-1=2$ & exactly identified \\
\hline$(17)$ & $3-2=1$ & $2-1=1$ & exactly identified \\
\hline$(18)$ & $3-2=1$ & $2-1=1$ & exactly identified \\
\hline$(19)$ & $3-1=2$ & $3-2=1$ & exactly identified \\
\hline
\end{tabular}

\subsection{Uji Spesifikasi Haussman}

Masalah utama dalam persamaan simultan adalah adanya variabel endogen eksplanatori yang berkorelasi dengan error, maka estimator OLS akan menghasilkan estimator yang bias dan tidak konsisten. Dengan alasan ini, maka dibutuhkan alternatif metode estimasi yang lain yang disebut metode Two Stage Least Square (2 SLS). Walaupun demikian, jika pada kasus nonsimultan digunakan metode 2 SLS maka hasil estimasinya akan konsisten namun tidak efisien. Sehingga dibutuhkan pemeriksaan apakah persamaan itu simultan atau tidak.

Uji kesimultanan pada dasarnya digunakan menguji apakah variabel endogen eksplanatori berkorelasi dengan eror atau tidak. Jika tidak terdapat korelasi, maka estimator OLS dapat digunakan. Pengujian yang digunakan untuk menguji kesimultanan adalah uji Haussman. Hipotesis yang dirumuskan, adalah sebagai berikut :

$$
\begin{aligned}
& H_{0} \text { : Tidak terdapat simultanitas (tidak terdapat korelasi) } \\
& H_{1} \text { : Terdapat simultanitas (terdapat korelasi) }
\end{aligned}
$$

Langkah-langkah dalam pengujian Haussman menurut Sseddighi dan Katos (2000) adalah sebagai berikut :

1. Mengestimasi persamaan tereduksi dari model persamaan simultan. Meregresikan variabel endogen di setiap persamaan struktural dengan regresor pada sisi kanan yang terdiri dari variabel predetermined. Simpan nilai $\widehat{Y}_{t}$ dan nilai sisaan $u_{t}$.

2. Karena $Y_{t}=\widehat{Y}_{t}+u_{t}$, maka subtitusikan bentuk ini pada persamaan yang mengandung variabel endogen eksplanatori tersebut, kemudian lakukan estimasi menggunakan OLS.

$$
\begin{aligned}
& Y_{i, t}=\alpha_{i, t}\left(\widehat{Y}_{t}+u_{t}\right)+\beta_{i, t} X_{i, t}+\varepsilon_{i, t} \\
& Y_{i, t}=\alpha_{i, t} \widehat{Y}_{t}+\alpha_{i, t} u_{t}+\beta_{i, t} X_{i, t}+\varepsilon_{i, t}
\end{aligned}
$$

3. Menggunakan uji individual untuk menguji kesignifikanan koefisien regresi dari variabel $u_{t}$ pada persamaan (20). Jika hasil yang didapatkan menunjukkan bahwa koefisien regresi dari variabel $u_{t}$ signifikan, maka $H_{0}$ ditolak, sehingga dapat disimpulkan bahwa terdapat simultanitas. Jika hasil yang didapatkan dari pengujian menunjukkan bahwa koefisien regresi dari variabel $u_{t}$ tidak signifikan, maka $H_{0}$ gagal ditolak, sehingga dapat disimpulkan bahwa tidak terdapat simultanitas.

\section{METODE PENELITIAN}

Langkah pertama yang harus dilakukan untuk menentukan metode estimasi pada model persamaan simultan adalah identifikasi persamaan. Jika masing persamaan struktural teridentifikasi secara tepat atau berlebihan maka metode estimasi yang digunakan pada sistem persamaan simultan adalah 2 SLS. Metode 2 SLS seperti namanya, 
merupakan penerapan dari OLS dalam dua tahap. Secara berturut-turut, berikut adalah prosedur estimasi dengan 2SLS :

1. Mencari bentuk tereduksi (reduced form) dari masing-masing persamaan struktural. Kemudian meregresikan nilai $Y_{i t}$ dengan semua variabel predetermined dengan OLS. Dari hasil regresi tahap pertama ini, didapatkan nilai $\widehat{Y}_{i t}$ yang tidak berkorelasi dengan error.

2. Mensubtitusikan nilai $\hat{Y}_{i t}$ pada $Y_{i t}$ yang berada pada sisi kanan di setiap persamaan struktural, kemudian lakukan estimasi model dengan OLS.

\section{HASIL DAN PEMBAHASAN}

\subsection{Estimasi Parameter Model Regresi Panel Dinamis dengan Variabel Eksogen Menggunakan GMM Arellano-Bond}

Masalah paling mendasar dari model data panel dinamis adalah adanya korelasi antara variabel lag endogen (yang berposisi sebagai variabel eksplanatori) dengan error, sehingga OLS akan menghasilkan estimasi yang bias dan tidak konsisten. Oleh karena itu digunakan metode estimasi GMM Arellano-Bond yang dapat menghasilkan estimasi parameter yang tak bias, konsisten, serta efisien.

Langkah-langkah estimasi parameter model regresi panel dinamis menggunakan GMM Arellano-Bond, adalah sebagai berikut :

1. Melakukan first differencing pada persamaan (3) untuk menghilangkan efek individu (Baltagi, 2005).

$$
\Delta y_{i, t}=\Delta y_{i, t-1} \delta+\Delta \boldsymbol{x}_{i, t}^{\prime} \boldsymbol{\beta}+\Delta v_{i t}
$$

Jika terdapat sebanyak $N$ observasi, $T$ periode waktu, dan $K$ variabel eksogen. Maka persamaan (21) dapat dijabarkan sebagai berikut:

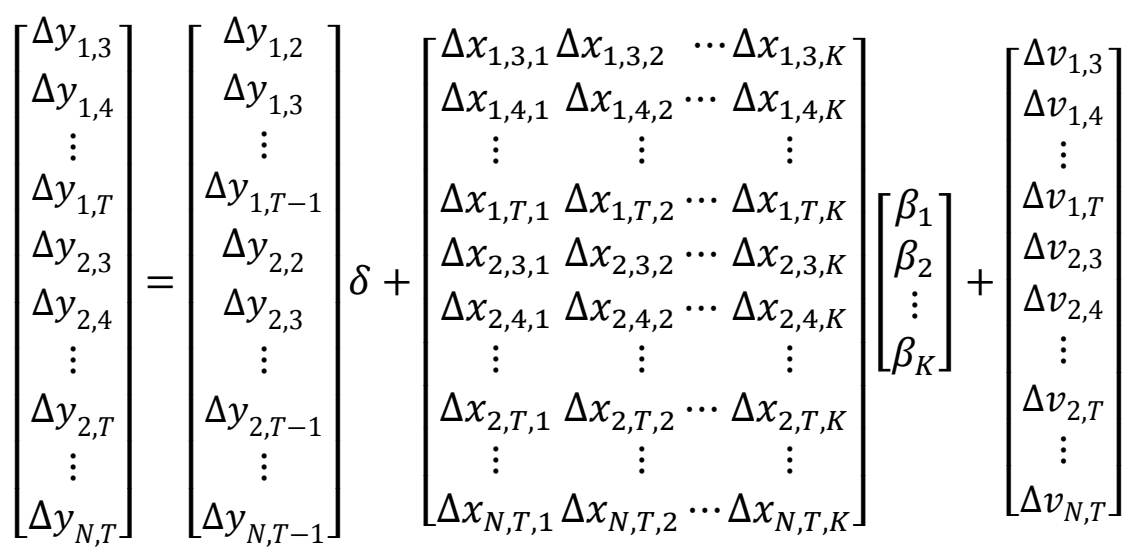

Matriks pada persamaan (22), dapat diringkas dalam bentuk berikut :

$$
\left[\begin{array}{c}
\Delta \boldsymbol{y}_{\mathbf{1}} \\
\Delta \boldsymbol{y}_{\mathbf{2}} \\
\vdots \\
\Delta \boldsymbol{y}_{\boldsymbol{N}}
\end{array}\right]=\left[\begin{array}{c}
\Delta \boldsymbol{y}_{1, \boldsymbol{t}-\mathbf{1}} \\
\Delta \boldsymbol{y}_{2, \boldsymbol{t}-\mathbf{1}} \\
\vdots \\
\Delta \boldsymbol{y}_{N, \boldsymbol{t}-\mathbf{1}}
\end{array}\right] \delta+\left[\begin{array}{ccc}
\Delta x_{1,1} & \Delta x_{1,2} \cdots & \Delta x_{1, K} \\
\Delta x_{2,1} & \Delta x_{2,2} \cdots & \Delta x_{2, K} \\
\vdots & \vdots & \vdots \\
\Delta x_{N, 1} & \Delta x_{N, 2} \cdots & \Delta x_{N, K}
\end{array}\right]\left[\begin{array}{c}
\beta_{1} \\
\beta_{2} \\
\vdots \\
\beta_{K}
\end{array}\right]+\left[\begin{array}{c}
\Delta \boldsymbol{v}_{1} \\
\Delta \boldsymbol{v}_{2} \\
\vdots \\
\Delta \boldsymbol{v}_{N}
\end{array}\right]
$$

dengan, 


$$
\begin{aligned}
& \Delta \boldsymbol{y}_{\boldsymbol{i}_{((\boldsymbol{T}-\mathbf{2}) \times \mathbf{1})}}=\left[\begin{array}{c}
\Delta y_{i, 3} \\
\Delta y_{i, 4} \\
\vdots \\
\Delta y_{i, T}
\end{array}\right] \quad \Delta \boldsymbol{y}_{\mathbf{1 , t - 1} \mathbf{1}_{((\boldsymbol{T}-\mathbf{2}) \times \mathbf{1})}}=\left[\begin{array}{c}
\Delta y_{i, 2} \\
\Delta y_{i, 3} \\
\vdots \\
\Delta y_{i, T-1}
\end{array}\right] \\
& \Delta x_{i, K}((\boldsymbol{T}-\mathbf{2}) \times \mathbf{1})=\left[\begin{array}{c}
\Delta x_{i, 3, K} \\
\Delta y_{i, 4, K} \\
\vdots \\
\Delta y_{i, T, K}
\end{array}\right] \quad \Delta \boldsymbol{v}_{i((\boldsymbol{T}-\mathbf{2}) \times \mathbf{1})}=\left[\begin{array}{c}
\Delta v_{i 3} \\
\Delta v_{i 4} \\
\vdots \\
\Delta v_{i T}
\end{array}\right]
\end{aligned}
$$

Dengan demikian persamaan (23) dapat disajikan dalam bentuk sebagai berikut:

$$
\Delta y_{i}=\Delta y_{i, t-1} \delta+\Delta x_{i, K}^{\prime} \beta+\Delta v_{i}
$$

Maka error adalah :

$$
\Delta v_{i}=\Delta y_{i}-\Delta y_{i, t-1} \delta-\Delta x_{i, K}^{\prime} \beta
$$

Dimisalkan

$$
\begin{aligned}
\boldsymbol{\gamma} & =\left(\begin{array}{c}
\delta \\
\beta_{1} \\
\vdots \\
\beta_{K}
\end{array}\right)=\left(\begin{array}{c}
\boldsymbol{\delta} \\
\boldsymbol{\beta}
\end{array}\right), \widehat{\boldsymbol{\gamma}}=\left(\begin{array}{c}
\hat{\delta} \\
\hat{\beta}_{1} \\
\vdots \\
\hat{\beta}_{K}
\end{array}\right)=\left(\begin{array}{c}
\widehat{\boldsymbol{\delta}} \\
\widehat{\boldsymbol{\beta}}
\end{array}\right) \text { dan } \\
\boldsymbol{Q} & =\left(\begin{array}{lll}
\boldsymbol{\Delta} \boldsymbol{y}_{i, t-1}, & \boldsymbol{\Delta} \boldsymbol{x}_{\boldsymbol{i 1}}, \quad \ldots, \quad \boldsymbol{\Delta} \boldsymbol{x}_{\boldsymbol{i}}
\end{array}\right)=\left(\begin{array}{l}
\boldsymbol{\Delta} \boldsymbol{y}_{i, t-1}, \quad \boldsymbol{\Delta} \boldsymbol{x}_{\mathbf{i}}
\end{array}\right),
\end{aligned}
$$

sehingga

$$
\Delta v_{i}=\Delta y_{i}-Q \gamma \cdot(26)
$$

2. Memformulasikan matriks instrumen. Arellano dan Bond (1991) menyatakan bahwa matriks instrumen yang valid untuk persamaan (21) adalah sebagai berikut:

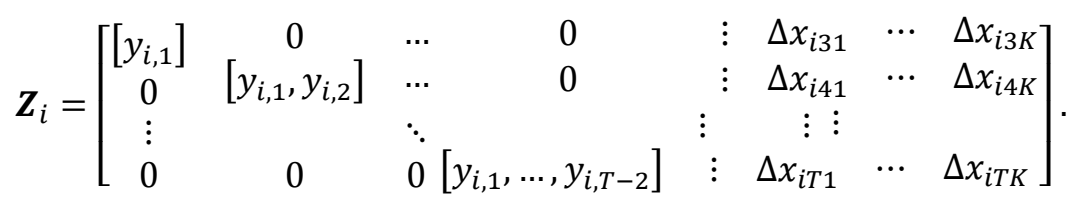

3. Memformulasikan momen kondisi populasi, yaitu :

$$
E\left(g_{i}(\boldsymbol{\gamma})\right)=E\left(\boldsymbol{Z}_{i}^{\prime} \boldsymbol{\Delta} \boldsymbol{v}_{\boldsymbol{i}}\right)=E\left(\boldsymbol{Z}_{i}^{\prime}\left(\Delta \boldsymbol{y}_{i}-\boldsymbol{Q} \boldsymbol{\gamma}\right)\right)=0
$$

4. Memformulasikan momen kondisi sampel, yaitu :

$$
\bar{g}(\boldsymbol{\gamma})=N^{-1} \sum_{i=1}^{N} \boldsymbol{Z}_{i}^{\prime}\left(\Delta \boldsymbol{y}_{i}-\boldsymbol{Q} \boldsymbol{\gamma}\right)
$$

5. Memformulasikan matriks bobot. Didefinisikan matriks $\widehat{W}$ yaitu taksiran tak bias dan konsisten untuk matriks bobot $\boldsymbol{W}_{(L \times L)}$ dimana $L$ adalah jumlah variabel instrumen. Arellano dan Bond (1991) mengusulkan bobot $\widehat{\boldsymbol{W}}$ yang optimal sebagai berikut :

$$
\widehat{W}=\widehat{\Lambda}^{-1}
$$

dengan 


$$
\widehat{\Lambda}=N^{-1} \sum_{i=1}^{N} Z_{i}^{\prime} \Delta v_{i} \Delta v_{i}^{\prime} Z_{i}
$$

6. Membangun fungsi GMM yaitu fungsi kuadratik dari momen sampel. Fungsi tersebut adalah sebagai berikut :

$$
J(\boldsymbol{\gamma})=\bar{g}(\boldsymbol{\gamma})^{\prime} \widehat{W} \bar{g}(\boldsymbol{\gamma})
$$

maka,

$$
\begin{aligned}
J(\boldsymbol{\gamma})= & {\left[N^{-1} \sum_{i=1}^{N} \boldsymbol{Z}_{i}^{\prime}\left(\Delta \boldsymbol{y}_{i}-\boldsymbol{Q} \boldsymbol{\gamma}\right)\right]^{\prime} \widehat{\boldsymbol{W}}\left[N^{-1} \sum_{i=1}^{N} \boldsymbol{Z}_{i}^{\prime}\left(\Delta \boldsymbol{y}_{i}-\boldsymbol{Q} \boldsymbol{\gamma}\right)\right] } \\
J(\widehat{\boldsymbol{\gamma}})= & \left(N^{-1} \sum_{i=1}^{N} \Delta \boldsymbol{y}_{i}^{\prime} \boldsymbol{Z}_{\boldsymbol{i}}\right) \widehat{\boldsymbol{W}}\left(N^{-1} \sum_{i=1}^{N} \boldsymbol{Z}_{i}^{\prime} \Delta \boldsymbol{y}_{i}\right) \\
& -2\left(N^{-1} \sum_{i=1}^{N} \Delta \boldsymbol{y}_{i}^{\prime} \boldsymbol{Z}_{\boldsymbol{i}}\right) \widehat{\boldsymbol{W}}\left(N^{-1} \sum_{i=1}^{N} \boldsymbol{Z}_{i}^{\prime} \boldsymbol{Q} \boldsymbol{\gamma}\right) \\
& +\left(N^{-1} \sum_{i=1}^{N} \boldsymbol{\gamma}^{\prime} \boldsymbol{Q}^{\prime} \boldsymbol{Z}_{\boldsymbol{i}}\right) \widehat{\boldsymbol{W}}\left(N^{-1} \sum_{i=1}^{N} \boldsymbol{Z}_{i}^{\prime} \boldsymbol{Q} \boldsymbol{\gamma}\right)
\end{aligned}
$$

Taksiran GMM untuk $\boldsymbol{\gamma}$ didapatkan dengan cara meminimumkan $J(\boldsymbol{\gamma})$.

$$
\begin{aligned}
& \frac{\partial J(\boldsymbol{\gamma})}{\partial(\widehat{\gamma})}=0 \\
& \frac{\partial J(\boldsymbol{\gamma})}{\partial(\widehat{\boldsymbol{\gamma}})}=-2\left(N^{-1} \sum_{i=1}^{N} \Delta \boldsymbol{y}_{i}^{\prime} \boldsymbol{Z}_{\boldsymbol{i}}\right) \widehat{\boldsymbol{W}}\left(N^{-1} \sum_{i=1}^{N} \boldsymbol{Z}_{i}^{\prime} \boldsymbol{Q}\right)+2\left(N^{-1} \sum_{i=1}^{N} \widehat{\gamma}^{\prime} \boldsymbol{Q}^{\prime} \boldsymbol{Z}_{\boldsymbol{i}}\right) \widehat{\boldsymbol{W}}\left(N^{-1} \sum_{i=1}^{N} \boldsymbol{Z}_{i}^{\prime} \boldsymbol{Q}\right) \\
& \widehat{\boldsymbol{\gamma}}=\left[\left(N^{-1} \sum_{i=1}^{N} \boldsymbol{Q}^{\prime} \mathbf{Z}_{\boldsymbol{i}}\right) \widehat{\boldsymbol{W}}\left(N^{-1} \sum_{i=1}^{N} \boldsymbol{Z}_{i}^{\prime} \boldsymbol{Q}\right)\right]^{-1}\left[\left(N^{-1} \sum_{i=1}^{N} \boldsymbol{Q}^{\prime} \boldsymbol{Z}_{\boldsymbol{i}}\right) \widehat{\boldsymbol{W}}\left(N^{-1} \sum_{i=1}^{N} \boldsymbol{Z}_{i}^{\prime} \Delta \boldsymbol{y}_{i}\right)\right] \\
& \left(\begin{array}{c}
\widehat{\boldsymbol{\delta}} \\
\widehat{\boldsymbol{\beta}}
\end{array}\right)=\left[\left(N^{-1} \sum_{i=1}^{N}\left(\boldsymbol{\Delta} \boldsymbol{y}_{i, t-1}, \Delta \boldsymbol{x}_{\boldsymbol{i}}\right)^{\prime} \boldsymbol{Z}_{i}\right) \widehat{\boldsymbol{W}}\left(N^{-1} \sum_{i=1}^{N} \boldsymbol{Z}_{i}^{\prime}\left(\Delta \boldsymbol{y}_{i, t-1}, \Delta \boldsymbol{x}_{\boldsymbol{i}}\right)\right)\right]^{-1} \\
& {\left[\left(N^{-1} \sum_{i=1}^{N}\left(\Delta \boldsymbol{y}_{i, t-1}, \Delta \boldsymbol{x}_{\boldsymbol{i}}\right)^{\prime} \boldsymbol{Z}_{i}\right) \widehat{\boldsymbol{w}}\left(N^{-1} \sum_{i=1}^{N} \boldsymbol{Z}_{i}^{\prime} \Delta \boldsymbol{y}_{i}\right)\right.} \\
& \frac{\partial J^{2}(\boldsymbol{\gamma})}{\partial(\widehat{\gamma})^{2}}=2\left(N^{-1} \sum_{i=1}^{N} \boldsymbol{Q}^{\prime} \boldsymbol{Z}_{\boldsymbol{i}}\right) \widehat{\boldsymbol{W}}\left(N^{-1} \sum_{i=1}^{N} \boldsymbol{Z}_{i}^{\prime} \boldsymbol{Q}\right)>0
\end{aligned}
$$

Analog dengan persamaan (5), hasil estimasi parameter pada persamaan (29) disebut one step consistent estimator GMM Arellano and Bond. Dengan mensubtitusikan bobot $\widehat{\boldsymbol{W}}$ dengan bobot optimal $\widehat{\boldsymbol{\Lambda}}^{-\mathbf{1}}$, maka didapatkan two step effisient estimator GMM Arellano and Bond, sebagai berikut: 


$$
\begin{aligned}
\left(\begin{array}{c}
\widehat{\boldsymbol{\delta}} \\
\widehat{\boldsymbol{\beta}}
\end{array}\right)= & {\left[\left(N^{-1} \sum_{i=1}^{N}\left(\Delta \boldsymbol{y}_{i, t-1}, \Delta \boldsymbol{x}_{\boldsymbol{i}}\right)^{\prime} \boldsymbol{Z}_{i}\right) \widehat{\boldsymbol{\Lambda}}^{-\mathbf{1}}\left(N^{-1} \sum_{i=1}^{N} \boldsymbol{Z}_{i}^{\prime}\left(\Delta \boldsymbol{y}_{i, t-1}, \Delta \boldsymbol{x}_{\boldsymbol{i}}\right)\right)\right]^{-1} } \\
& {\left[\left(N^{-1} \sum_{i=1}^{N}\left(\Delta \boldsymbol{y}_{i, t-1}, \Delta \boldsymbol{x}_{\boldsymbol{i}}\right)^{\prime} \boldsymbol{Z}_{i}\right) \widehat{\boldsymbol{\Lambda}}^{-\mathbf{1}}\left(N^{-1} \sum_{i=1}^{N} \boldsymbol{Z}_{i}^{\prime} \Delta \boldsymbol{y}_{i}\right)\right.}
\end{aligned}
$$

Estimasi yang konsisten untuk matriks varian dan kovarian untuk vektor $\left(\begin{array}{l}\widehat{\boldsymbol{\delta}} \\ \widehat{\boldsymbol{\beta}}\end{array}\right)$ yang asimtotik menurut Baltagi (2005) adalah suku pertama dari persamaan (30).

$$
\boldsymbol{V}\left(\begin{array}{c}
\widehat{\boldsymbol{\delta}} \\
\widehat{\boldsymbol{\beta}}
\end{array}\right)=\left[\left(N^{-1} \sum_{i=1}^{N}\left(\Delta \boldsymbol{y}_{i, t-1}, \Delta \boldsymbol{x}_{\boldsymbol{i}}\right)^{\prime} \boldsymbol{Z}_{i}\right) \widehat{\boldsymbol{\Lambda}}^{-\mathbf{1}}\left(N^{-1} \sum_{i=1}^{N} \boldsymbol{Z}_{i}^{\prime}\left(\boldsymbol{\Delta} \boldsymbol{y}_{i, t-1}, \Delta \boldsymbol{x}_{\boldsymbol{i}}\right)\right)\right]^{-1}
$$

Hasil estimasi parameter pada persamaan (29) sudah memenuhi syarat sebagai estimator konsisten karena

$$
\lim _{n \rightarrow \infty}\left[\left(N^{-1} \sum_{i=1}^{N}\left(\boldsymbol{\Delta} \boldsymbol{y}_{i, t-1}, \boldsymbol{\Delta} \boldsymbol{x}_{\boldsymbol{i}}\right)^{\prime} \boldsymbol{Z}_{i}\right) \widehat{\boldsymbol{\Lambda}}^{-\mathbf{1}}\left(N^{-1} \sum_{i=1}^{N} \boldsymbol{Z}_{i}^{\prime}\left(\boldsymbol{\Delta} \boldsymbol{y}_{i, t-1}, \boldsymbol{\Delta} \boldsymbol{x}_{\boldsymbol{i}}\right)\right)\right]^{-1}=0
$$

\subsection{Langkah Estimasi Parameter Persamaan Simultan Data Panel Dinamis GMM Arellano-Bond}

Langkah pertama yang harus dilakukan untuk menentukan metode estimasi pada model persamaan simultan adalah identifikasi persamaan. Jika masing-masing persamaan struktural teridentifikasi secara tepat atau berlebihan maka metode estimasi yang digunakan pada sistem persamaan simultan adalah 2SLS. Dalam sistem persamaan simultan data panel dinamis, masing-masing persamaan struktural merupakan persamaan regresi data panel dinamis dengan variabel eksogen. Salah satu variabel eksogen yang terdapat pada masing-masing persamaan struktural merupakan variabel endogen eksplanatori. Berikut adalah langkah-langkah estimasi parameter persamaan simultan data panel dinamis dengan 2 SLS :

1. Mengestimasi nilai dari variabel endogen melalui bentuk tereduksi menggunakan GMM Arellano-Bond.

2. Mengestimasi persamaan struktural dengan mensubtitusi variabel endogen pada sisi kanan dengan estimasi variabel endogen yang telah didapatkan pada langkah 1 menggunakan GMM Arellano-Bond.

Dengan demikian, rangkaian metode estimasi ini kemudian dinamakan Two Stage Least Square Generalized Method of Moment Arellano and Bond (2 SLS GMM AB).

\subsection{Penerapan Metode 2 SLS GMM-AB}

Metode 2 SLS GMM-AB dapat diaplikasikan pada kasus ekonomi. Shina (2016) melakukan penelitian mengenai hubungan dua arah yang negatif antara variabel tingkat pengangguran dan pertumbuhan ekonomi Indonesia menggunakan data 33 provinsi selama lima tahun. Berdasarkan penelitian tersebut didapatkan kesimpulan bahwa ada hubungan 
yang simultan antara tingkat pengangguran dan pertumbuhan ekonomi. Tingkat pengangguran akan menurun secara jangka pendek sebesar $0,9562 \%$ dan secara jangka panjang sebesar $0,9880 \%$ apabila pertumbuhan ekonomi naik sebesar $1 \%$. Sedangkan pertumbuhan ekonomi akan mengalami perlambatan secara jangka pendek sebesar $0,4651 \%$ dan secara jangka panjang sebesar $0,6154 \%$ apabila terjadi peningkatan tingkat pengangguran sebesar 1\%. Di sisi lain Mankiw (2010) menyatakan bahwa tingkat pengangguran yang tinggi dapat menyebabkan kekacauan politik, keamanan, dan sosial sehingga tentunya dapat mengganggu pertumbuhan ekonomi suatu negara. Sedangkan pertumbuhan ekonomi yang mendekati $2 \%$ akan mengurangi pengangguran sebesar $1 \%$.

\section{KESIMPULAN}

Estimasi parameter sistem persamaan simultan dengan data panel dinamis menggunakan prinsip 2SLS, dimulai dengan mengestimasi parameter pada bentuk tereduksi (reduced form) kemudian dilanjutkan mengestimasi parameter pada persamaan struktural. Kedua proses estimasi ini menggunakan metode GMM Arellano dan Bond. Oleh karena itu metode estimasi ini dinamakan Two Stage Least Square Generalized Method of Moment Arellano and Bond (2 SLS GMM-AB).

Metode estimasi 2 SLS GMM-AB dapat diaplikasikan pada bidang ekonomi. Di bidang ekonomi terdapat variable-variabel yang bersifat dinamis dan saling berhubungan dua arah. Misalnya hubungan dua arah yang negatif antara pertumbuhan ekonomi dan tingkat pengangguran.

\section{DAFTAR PUSTAKA}

Anderson, T. W. dan Hsiao, C. 1982. Formulation And Estimation of Dynamic Models Using Panel Data. Journal of Economic, 47-82.

Arellano, M. dan Bond, S. 1991. Some Test of Specification for Panel Data : Monte Carlo Evidence and an Application to Employment Equations. The Review of Economic Studies, Vol. 58, 277-297.

Baltagi, B. H. 2005, Econometric Analysis of Panel Data, New York: John Wiley dan Sons.

Gujarati, D.N. dan Porter, D.C. 2012. Dasar-dasar Ekonometrika. Edisi ke-5 Buku 2. Diterjemahkan oleh: Carlos Mengunsong. Jakarta: Salemba Empat.

Lai, T. L., Small, D.S., dan Liu, J., 2008. Statistical Inference in Dynamic Panel Data Models. Journal of Statistical Planning and Inference, Vol. 138, 2763-2776.

Mankiw, N. G. 2010. Macroeconomic. 7ed. New York: Worth.

Shina, A.F.I. 2016. Penerapan 2 SLS GMM-AB pada Persamaan Data Panel Dinamis untuk Pemodelan Pertumbuhan Ekonomi Indonesia sebagai Islamic Country. Jurnal Muqtasid,. Vol. 7, 141-162.

Sseddighi, L. dan Katos. 2000. Econometrics A Practical Approch, London: Routledge. 